\title{
SISTEM PAKAR MENDETEKSI KERUSAKAN SEPEDA MOTOR N- MAX MENGGUNAKAN METODE FORWARD CHAINING BERBASIS ANDROID
}

\author{
Jepon Aprilion Wahyudin Simamora \\ CV Morani Mandiri Sejahtera, Central Java, Indonesia \\ e-mail: wahyudinsimamora58@gmail.com
}

\begin{abstract}
Abstrak
Perkembangan industri sepeda motor matic injeksi di indonesia mengalami perkembangan yang sangat signifikan, sepeda motor matic injeksi yang lebih irit bahan bakar dan ramah lingkungan, dengan tingginya pengguna sepeda motor matic injeksi saat ini timbul permasalahan bahwa tidak semua pengguna motor matic injeksi memiliki kemampuan melakukan perbaikan terhadap kerusakan sepeda motornya. Dengan kemajuan teknologi smartphone saat ini, memunculkan suatu ide atau gagasan aplikasi sistem pakar ke dalam aktivitas mutu pelayanan smartphone. Sistem yang akan dibuat adalah "Sistem pakar mendeteksi kerusakan sepeda motor N-Max menggunakan metode forward chaining berbasis android". Sistem pakar ini dapat membantu pengguna mengetahui kerusakan dan melakukan perbaikan sepeda motornya lebih awal sebelum terjadi kerusakan yang berkelanjutan.
\end{abstract}

Kata Kunci: Motor matic injeksi, Sistem pakar, Forward chaining

\section{Expert System To Detect Damage To N-Max Motorbikes Using Forward chaining Method Based on Android}

\begin{abstract}
The development of the automatic injection motorcycle industry ini indonesia experienced a very significant development, matic injection motorcycles are more fuel efficient and environmentally friendly, with the high number of automatoc injrction motorcycle user a problem arises that not all injection motorcycle users have the ability to make repairs to thr damage to their motorbikes. With current smartphone technology advancements, bring up an idea or expert system application ideas into smarthphone service quality activities. The system that will be created is "Expert system to detect damage to N-Max motorbikes using Forward chaining method based on Android". The expert system is to help the user know the damage and make repairs to his motorcycle earlier before there is ongoing damage.
\end{abstract}

Keywords: Automatic injection motor, expert system, forward chaining

\section{Pendahuluan}

Perkembangan dunia otomotif serta pemasarannya pada era globalisasi sekarang ini telah berkembang menjadi begitu kompleks dan begitu penuh dengan inovasi-inovasi yang dilakukan oleh para pelakunya [1]. Sepeda motor saat ini sudah menjadi sangat penting bagi setiap orang, di samping untuk alat transportasi sepeda motor juga digunakan untuk menambah penghasilan bagi sebagian profesi tertentu. Persaingan pada perusahaan otomotif di Indonesia semakin ketat, dimana hal tersebut dipengaruhi oleh meningkatnya kebutuhan masyarakat terhadap sepeda motor. Setiap orang selalu mendambakan kendaraan sepeda motor yang sehat tanpa ada gangguan dan kerusakan, karena gangguan dan kerusakan yang terjadi pada sepeda motor bisa menyebabkan sepeda motor menjadi tidak bermanfaat dan tidak 
berfungsi. Oleh karena itu untuk mengatasinya kita harus mengetahui jenis kerusakan yang terjadi serta solusi dan cara memperbaikinya. Untuk dapat memberikan suatu informasi tentang bagaimana mendiagnosa kerusakan sepeda motor, dibutuhkan suat aplikasi sistem pakar yang bisa mewakili seorang pakar yang ahli di bidangnya untuk memberikan solusi terhadap permasalahan yang dihadapi pengendara. Selain itu juga sistem pakar dapat meningkatkan produktivitas kerja, menghemat waktu dalam menyelesaikan masalah, penyederhanaan solusi untuk kasus-kasus yang kompleks dan berulang-ulang [2] [3].

Sistem pakar merupakan suatu sistem yang dibangun untuk memindahkan kemampuan dari seorang atau beberapa orang pakar dalam sistem yang digunakan untuk memecahkan masalah yang dihadapi oleh pemakai dalam bidang tertentu [4]. Dalam kasus ini penulis membuat sebuah sistem pakar untuk mendiagnosa kerusakan sepeda motor. Adapun penelitian ini muncul memiliki tujuan untuk memberikan pengetahuan tentang perawatan kerusakan sepeda motor kepada pengendara sehingga kerusakan pada sepeda motor dapat di tangani oleh pengendara itu sendiri. Penelitian ini juga meningkatkan kinerja dari suatu bengkel dalam mengatasi permintaan konsumen yang meningkat, dapat digunakan sebagai saran pelatihan bagi tenaga ahli atau pakar dalam mendeteksi kerusakan sepeda motor.

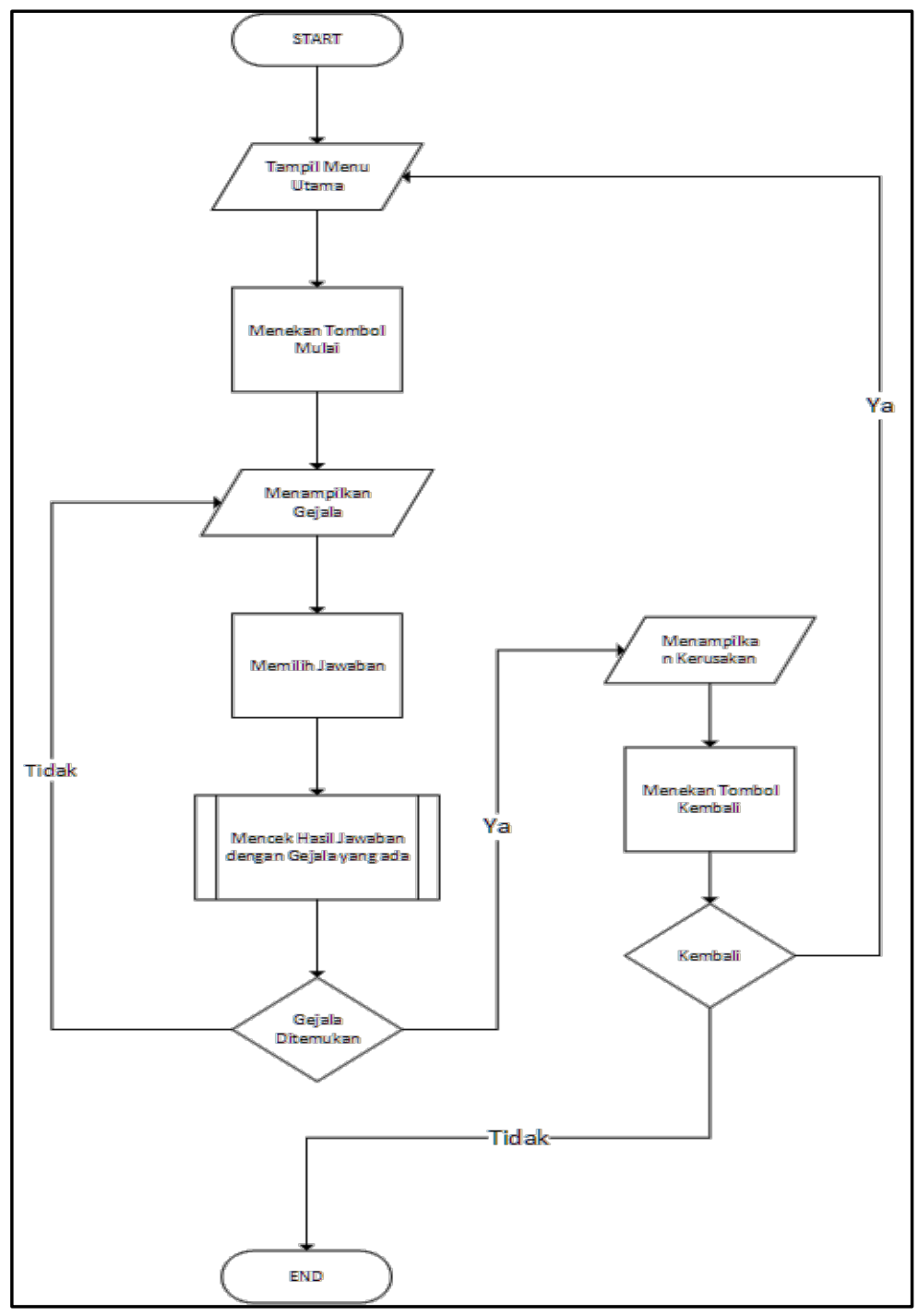

Gambar 1 Algoritma Forward chaining 


\section{Metode Penelitian}

\section{Analisis Kebutuhan Sistem}

Analisis kebutuhan sistem sangat dibutuhkan dalam mendukung kerja sistem. Apakah sistem yang dibuat sudah sesuai dengan yang dibutuhkan atau belum, karena kebutuhan sistem juga akan mendukung tercapainya tujuan suatu instansi atau perusahaan [5]. Dengan adanya sistem baru yang telah dibuat diharapkan dapat lebih membantu untuk mempermudah pengguna motor injeksi dalam memperoleh informasi - informasi yang diperlukan untuk mempermudah analisis sistem dalam menentukan kerusakan sepeda motor N-Max.

\section{A. Perancangan Forward chaining}

Perancangan Forward chaining merupakan suatu rancangan yang digunakan untuk membangun sebuah sistem pakar [6]. Di dalam Gambar 1, perancangan ini akan dicari hasil akhir dari setiap gejala. Perancangan sebagaimana digambarkan pada Gambar 1. Adapun tahapan yang dilakukan adalah sebagai berikut:

\section{Data Gejala dan Data Kerusakan}

Data gejala dan data kerusakan berisi tentang kerusakan gejala dan kerusakan motor N-Max Yang diperoleh dari seorang pakar.

Tabel 1 Data Gejala dan Data Kerusakan

\begin{tabular}{|c|c|c|c|c|c|c|c|c|}
\hline \multirow{2}{*}{ NO } & \multirow{2}{*}{ Gejala } & \multicolumn{7}{|c|}{ Kode Kerusakan } \\
\hline & & K1 & K2 & K3 & K4 & K5 & K6 & K7 \\
\hline 1 & G1 & $*$ & & $*$ & & & & \\
\hline 2 & G2 & $*$ & & & & & & \\
\hline 3 & G3 & & $*$ & & & & & \\
\hline 4 & G4 & & $*$ & $*$ & & & & \\
\hline 5 & G5 & & $*$ & & & & & \\
\hline 6 & G6 & & & & $*$ & & & \\
\hline 7 & G7 & & & & $*$ & & & \\
\hline 8 & G8 & & & $*$ & & & & \\
\hline 9 & G9 & & & $*$ & & $*$ & $*$ & \\
\hline 10 & G10 & & & & & $*$ & $*$ & \\
\hline 11 & G11 & & & & $*$ & & \\
\hline 12 & G12 & & & & & & $*$ & \\
\hline 13 & G13 & & & & & & $*$ \\
\hline 14 & G14 & & & & & & & $*$ \\
\hline 15 & G15 & & & & & & & $*$ \\
\hline
\end{tabular}

A. Keterangan kode kerusakan :

K1 : Tensioner

K2 : V-Belt

K3 : Laker Noken As

K4 : Race Ball Kit

K5 : Kerusakan Injektor

K6 : ECM

K7 : Kerusakan Busi

B. Keterangan Gejala Kerusakan :

G1 : Suara mesin kasar

G2 : Tarikan kendaraan berat 
G3 : Karet retak - retak

G4 : Suara mesin CVT menjadi berisik

G5 : Stang stir terasa kaku saat berkendara jauh

G6 : Terasa oleng saat di tikungan

G7 : Tarikan kendaraan terasa molor

G8 : Distater Sulit

G9 : Kecepatan tidak stabil

G10 : Distater manual dan listrik sulit

G11 : Bahan bakar boros

G12 : Motor mati/tidak bisa hidup sama sekali

G13 : Distater manual sulit

G14 : Knalpot sering meletus

G15 : Keluar asap hitam pada knalpot

\section{Aturan Data}

Baris aturan yang terdiri dari data gejala dan data kerusakan digabungkan sesuai dengan apa keputusan yang diambil oleh seorang pakar, serta tabel keputusan yang kemudian disusun dalam bentuk aturan dengan menggunakan metode forward chaining [7] yang dapat dilihat pada tabel berikut:

Tabel 2 Aturan Data

\begin{tabular}{|c|l|}
\hline Aturan (Rule) & \multicolumn{1}{|c|}{ Kaidah Produksi (AND) } \\
\hline R1 & IF G1 AND G2 THEN K1 \\
\hline R2 & IF G3 AND G4 AND G5 THEN K2 \\
\hline R3 & IF G1 AND G4 AND G8 AND G9 THEN K3 \\
\hline R4 & IF G6 AND G7 THEN K4 \\
\hline R5 & IF G9 AND G10 AND G11 THEN K5 \\
\hline R6 & IF G9 AND G10 AND G12 THEN K6 \\
\hline R7 & IF G13 AND G14 AND G15 THEN K7 \\
\hline
\end{tabular}

\section{B. Use Case Diagram}

Dalam perancangan sebuah sistem, diperlukan suatu diagram yang dinamakan use case untuk dipahami yang dapat dilakukan oleh user sebelum dikembangkan, berikut adalah fungsi yang dijelaskan dalam bentuk use case diagram [8].

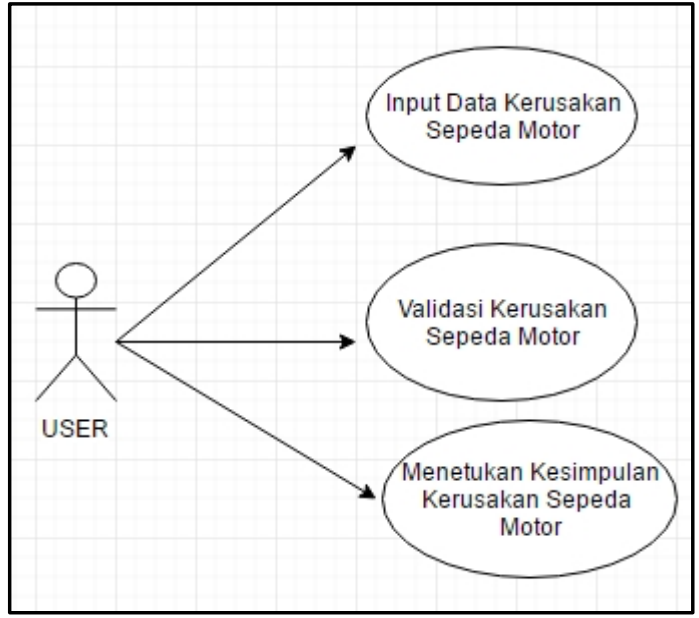

Gambar 3 Use case diagram 


\section{Activity Diagram}

Activity diagram menjelaskan bagaimana kegiatan yang user lakukan dengan fungsi yang ada secara bertahap. Activity diagram ditampilkan seperti sekat yang mewakili tiap langkah, seperti user dan komponen yang terlibat dalam menjalankan fungsi tertentu [9].

\section{Activity diagram data kerusakan}

Setelah user menjalankan aplikasi, user akan memasukkan informasi kerusakan yang dialami.

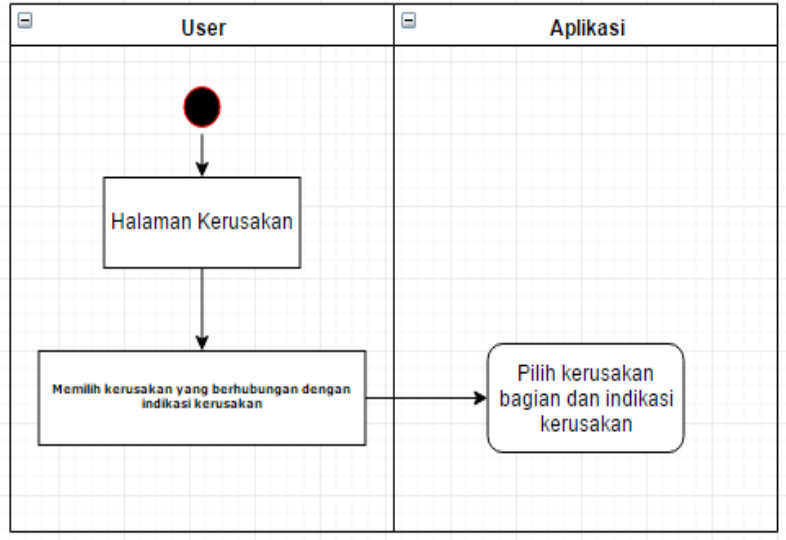

Gambar 4 Activity diagram input kerusakan

\section{Activity diagram hasil konsultasi}

Setelah usermemasukkan informasi kerusakan yang dialamai, userakan di arahkan ke halaman hasil konsultasi kerusakan sepeda motor.

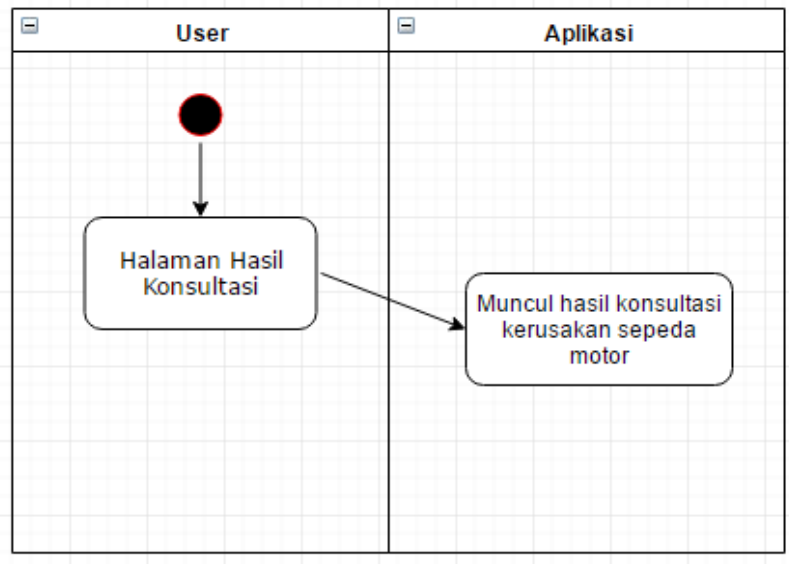

Gambar 5 Activity diagram hasil konsultasi

\section{Sequence Diagram}

Sequence diagram adalah salah satu komponen yang bertujuan untuk memberitahu bagaimana cara kerja setiap objek dari awal hingga akhir [10].

\section{Sequence diagram input kerusakan}

Sequence diagram input kerusakan ini adalah langkah dimana user berinteraksi degan sistem dari memilih kerusakan sepeda motor yang dialami. 


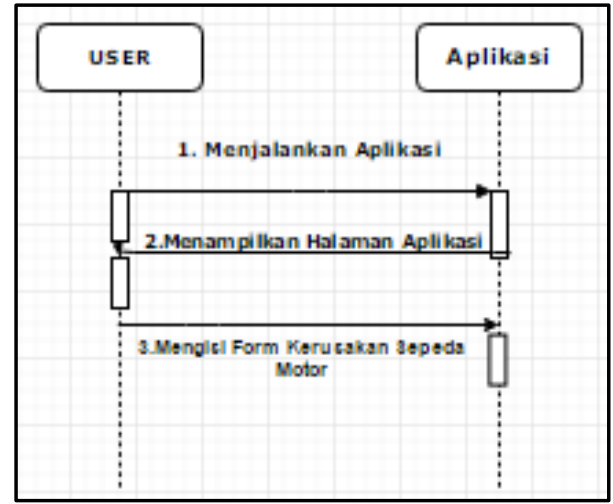

Gambar 6 Sequence diagram input kerusakan

\section{Sequence diagram Gejala-gejala Kerusakan}

Sequence diagram gejala kerusakan ini adalah langkah dimana aplikasi menunjukkan ciriciri kerusakan sepeda motor yang dialami oleh sepeda motor tersebut.

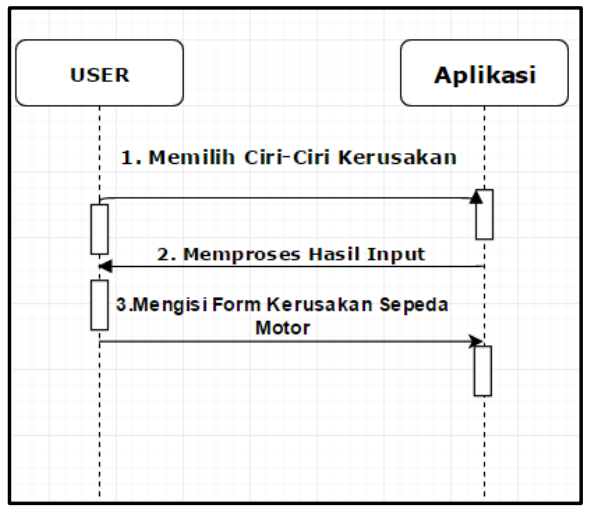

Gambar 7 Sequence diagram gejala kerusakan

\section{Sequence diagram hasil konsultasi}

Sequence diagram hasil konsultasi ini adalah langkah terakhir dimana usermenerima hasil keruskan yang sudah di input.

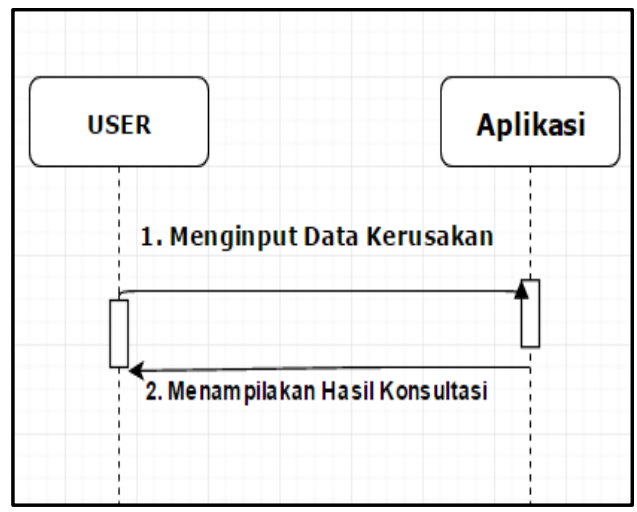

Gambar 8 Sequence diagram hasil konsultasi 


\section{E. Class Diagram}

Diagram ini berfungsi untuk menghubungkan 1 tabel atau tampilan ke tampilan lainya yang ada dalam aplikasi.

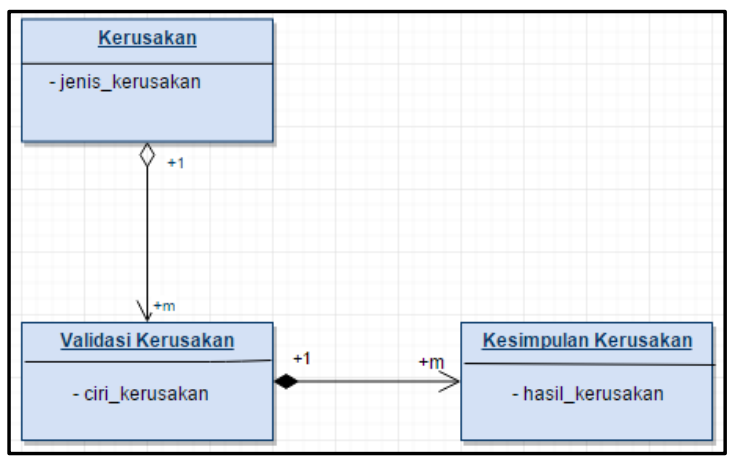

Gambar 9 Class Diagram

\section{Hasil}

\section{Hasil dan Perancangan Sistem}

Aplikasi yang telah dirancang terdiri dari tampilan utama, tampilan ciri-ciri kerusakan, tampilan hasil konsultasi, dan tampilan tidak ada kerusakan.

1. Halaman Utama

Halaman ini merupakan halaman yang akan pertama kali pengguna kalo lihat saat membuka aplikasi. Sebagaimana terdapat pada Gambar 1.

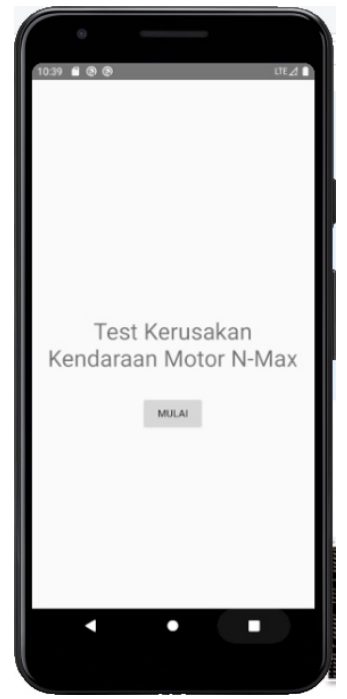

Gambar 1 Halaman Utama

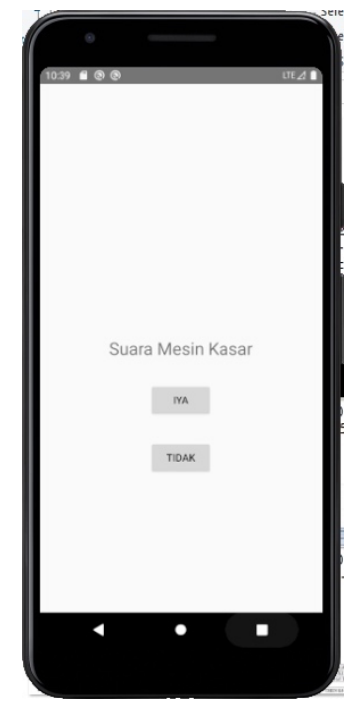

Gambar 2 Halaman Ciri-ciri Kerusakan

\section{Tampilan Ciri-Ciri Kerusakan}

Pada halaman ini (Gambar 2), pengguna dapat memilih kerusakan apa saja yang dirasakan sat mengendarai sepeda motor $\mathrm{N}$-Max. Jika pengguna merasakan kerusakan tersebut pengguna menekan tombol 'Ya' jika tidak pengguna dapat menekan tombol 'Tidak'. 
3. Tampilan Hasil Konsultasi

Pada bagian ini (Gambar 3), pengguna mendapatkan hasil kerusakan dari ciri-ciri yang sudah dipilih oleh pengguna di dalam halaman ciri-ciri kerusakan sebelumnya.

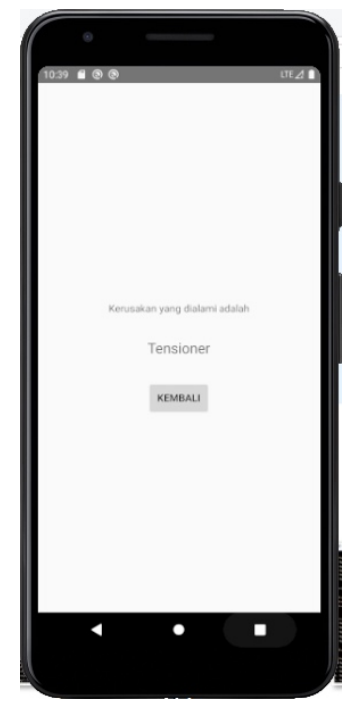

Gambar 3 Hasil Konsultasi

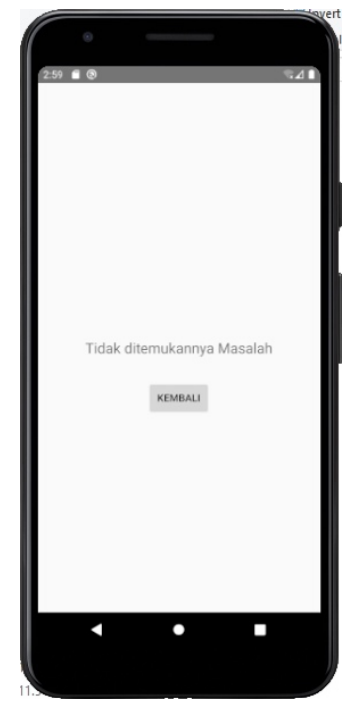

Gambar 4 Halaman tidak ada kerusakan

4. Halaman Tidak Ada Kerusakan

Halaman ini (Gambar 4) jika pengguna tidak menemukan ciri-ciri atau memilih tidak, aplikasi akan mengarahkan ke halaman ini.

\section{Pembahasan/Kesimpulan}

Berdasarkan permasalahan yang dibangun pada aplikasi sistem pakar untuk diagnosa kerusakan pada sepeda motor N-Max berbasis android, maka dapat diambil beberapa kesimpulan adalah sebagai berikut:

1. Aplikasi yang dibangun diharapkan dapat membantu para pengguna sepeda motor N-Max untuk mengetahui kerusakan sepeda motor berdasarkan gejala-gejala yang ada.

2. Berdasarkan dari hasil aplikasi ini yang menggunakan metode forward chaining di dapatkan kesimpulan yang sesuai dari kerusakan dan gejala pengguna motor N-Max untuk mengetahui kerusakan sepeda motornya.

Saran yang dapat diberikan untuk pengembangan sistem pakar mendeteksi kerusakan sepeda motor $\mathrm{N}-$ Max menggunakan metode forward chaining ini agar menjadi lebih baik antara lain :

1. Penelitian lanjutan dapat dikembangkan untuk diagnosa kerusakan sepeda motor matic lainnya, dan sepeda motor non matic.

2. Penelitian lanjutan dapat dikembangkan untuk diagnosa kerusakan sepeda motor N-max ke platform yang lainnya. 


\section{Referensi}

[1] T. Sandi, "ANALISIS KINERJA INDUSTRI OTOMOTIF (ISIC 29100) DI INDONESIA," Fakultas Ekonomi, Universitas Sriwijaya, Palembang, 2020.

[2] S. Y. C. Wardani, A. Maulana, A. Fauzi and Fahrizal, "Sistem Pakar Pendeteksi Kerusakan Pada Hardware Komputer Berbasis Android," Jurnal Ilmiah Teknik Informatika, vol. 10, no. 1, pp. 1-11, 2021.

[3] R. Maulany, "Pendekatan Metode Certainty Factor dalam Perancangan Sistem Pakar Kerusakan Komputer," TeIKa, vol. 5, no. 2, pp. 23-35, 2013.

[4] Kusrini, Sistem Pakar, Yogyakarta: Penerbit Andi, 2006.

[5] M. H. Prayitno, "Analisa Kebutuhan Sistem Informasi Dengan Menggunakan Analisis Value Change Dan Critical Success Factor Pada PT. LHE," BINA INSANI ICT JOURNAL, vol. 3, no. 1, pp. 269-278, 2016.

[6] A. R. Sihombing, "DESIGN OF EXPERT IDENTIFICATION SYSTEM USING FORWARD CHAINING METHOD ON ANDROID," TeIKa, vol. 10, no. 2, pp. 143-159, 2020.

[7] David, "Penerapan Rule Based Forward chaining pada Sistem Pakar untuk Diagnosa Penyakit Kulit," in Konferensi Nasional Sistem Informasi, Pangkal Pinang, Kalimantan, 2018.

[8] Munawar, Pemodelan Visual dengan UML, Yogyakarta: Graha Ilmu, 2009.

[9] Suendri, "Implementasi Diagram UML (Unified Modelling Language) Pada Perancangan Sistem Informasi Remunerasi Dosen Dengan Database Oracle (Studi Kasus: UIN Sumatera Utara Medan)," ALGORITMA: Jurnal IImu Komputer dan Informatika, vol. 3, no. 1, pp. 1-9, 2018.

[10] I. K. Raharjana and A. Justifia, "PEMBUATAN MODEL SEQUENCE DIAGRAM DENGAN REVERSE ENGINEERING APLIKASI BASIS DATA PADA SMARTPHONEUNTUK MENJAGA KONSISTENSI DESAIN PERANGKAT LUNAK," JUTI: Jurnal IImiah Teknologi Informasi, vol. 13, no. 2, pp. 133-142, 2015. 